\title{
Fluorescence In Situ Hybridization Method for Measuring Transfection Efficiency
}

BioTechniques 21:486-491 (September 1996)

\section{Lie Cheng, Corazon D. Bucana and Qingyi Wei}

The University of Texas M.D. Anderson Cancer Center, Houston, TX, USA
FISH method is a highly sensitive, specific and direct measure of transfection efficiency of a transient expression vector and that it may be useful for evaluating laboratory assays in which the quantitative aspects of transfection and the effect of plasmid DNA damage on transfection efficiency are important.

\section{INTRODUCTION}

Measuring the transfection efficiency of transient expression vectors, such as pRSVcat (23) and pCMVcat (2), which contain the gene encoding chloramphenicol acetyltransferase (CAT), has been a challenge. The advantage of using CAT is that mammalian cells do not have this bacterial gene. pCMVcat, which contains the human cytomegalovirus immediate enhancer and promoter (7), has sensitive and specific characteristics desirable for the hostcell reactivation (HCR) assay, which has been used in population studies to measure the DNA repair capacity of human lymphocytes $(2,25)$. However, a fundamental question about using the HCR assay for population studies is whether the cells being compared have the same transfection efficiencies and whether the transfection efficiencies of damaged and undamaged vectors are the same.

The transfection efficiency of plasmids containing the CAT gene reportedly varies in different cell types when measured by different transfection methods such as lipofection (6), electroporation (18), calcium phosphate precipitation (1) and diethylaminoethyl (DEAE)-dextran transfection (8) and also depends on the method used to measure the efficiency, such as antiCAT antibody detection (13) or cotransfection (15). The most commonly used methods of measuring transfection efficiency of a transient expression vector are based on cotransfection with another vector containing a different reporter gene, such as $\beta$-galactosidase ( $\beta$ gal) (9), luciferase (5) and tartrateresistant acid phosphatase (21). The underlying assumption for cotransfection is that transfection efficiency and expression efficiency are the same for both the target plasmid (e.g., encoding $\mathrm{CAT}$ ) and the marker plasmid (e.g., encoding $\beta$-gal), regardless of their different sizes and structures. Although adherent cells such as fibroblasts can be stably cotransfected, the efficiency of cotransfection, particularly with transient expression vectors, is low in nonadherent cells such as lymphoblasts.

In addition, the shortcomings of cotransfection are the relatively high background staining in untransfected cells and the fact that gene expression cannot be measured until 24-48 h after transfection (15). Cell viability after transfection also varies, depending on the method of transfection used (for instance, electroporation kills some cells). Thus, the number of cells count- 
ed after transfection may be different from the number actually transfected. Therefore, the expression of reporter genes measured at a later time may not reflect the efficiency (the percentage of the cells) of initial transfection per se. This is particularly important when the transfection efficiency of a nicked plasmid is being evaluated, because the expression of nick-transfected plasmids can be reduced by the conversion of the circular plasmids to the linear form by endonuclease $(12,26)$ or simply by the failure of the linearized form to be transfected. To evaluate the transfection efficiency of such damaged plasmids, it would be best to identify the cells containing the transfected DNAs immediately after the transfection. This is not possible with the cotransfection method, which requires that time be allowed for expression of another cotransfected marker gene to evaluate transfection efficiency by analysis of the activity of the gene product (e.g., $\beta$-gal).

The recent development of the fluorescence in situ hybridization (FISH) techniques $(3,14,19,22)$ allows the use of specific probes to locate and map target genes to their chromosomes (11, 14,16). Using this powerful technique, one can detect single-copy genes or DNA sequences as small as $2.3 \mathrm{~kb}(24)$. Because the FISH technique is both highly sensitive and specific, we used it to measure the transfection efficiency of the transient expression vector pCMVcat by a standard transfection method, DEAE-dextran transfection, and compared FISH with the cotransfection method of measuring transfection efficiency.

\section{MATERIALS AND METHODS}

\section{Cell Lines and Cell Culture}

The fibroblast cell lines GM03377B (a normal line) and GM05509B (xeroderma pigmentosum group A line [XPA]) and lymphoblast cell lines GM00892B and GM00131A (normal lines) and GM02345B and GM02246B (XP$\mathrm{A}$ and XP-C lines, respectively) were purchased from the National Institute of General Medical Sciences Human Genetic Mutant Cell Repository (Camden, NJ, USA). The lymphoblasts were grown in suspension at $37^{\circ} \mathrm{C}$ in a $95 \%$ air and $5 \% \mathrm{CO}_{2}$ atmosphere in RPMI1640 medium supplemented with $15 \%$ fetal bovine serum (Life Technologies, Gaithersburg, MD, USA) without antibiotics. The fibroblasts were grown in minimum essential medium supplemented with $10 \%$ fetal bovine serum under the same conditions used for the lymphoblasts.

\section{The HCR Assay}

Purified pCMVcat (5 kb; a gift from Dr. Lawrence Grossman, Johns Hopkins University) was dissolved in TrisHCl-EDTA solution ( $\mathrm{pH} 7.9)$ at a concentration of $50 \mu \mathrm{g} / \mathrm{mL}$. pCMVcat damaged by exposure to $800 \mathrm{~J} / \mathrm{m}^{2}$ ultraviolet (UV) light and undamaged pCMVcat were transfected into the cells (ca. $0.125 \mu \mathrm{g}$ of plasmid per $1 \times$ $10^{6}$ cells) by the DEAE-dextran procedure (17). The HCR assay protocol does not require treatment of cells with sodium butyrate (2). In parallel experiments, the plasmid pCMVßgal (7.2 kb; provided by Dr. Francis Ali-Osman, The University of Texas M.D. Anderson Cancer Center) was also cotransfected with pCMVcat by the same procedure used for pCMVcat transfection, except that $0.25 \mu \mathrm{g}$ of undamaged pCMV $\beta$ gal per $1 \times 10^{6}$ cells was added to the transfection cocktail. The fibroblasts were transfected in six-well plates and the lymphoblasts were transfected in plastic tubes $(12 \mathrm{~mm} \times 75 \mathrm{~mm})$. After transfection, the cells were incubated for $40 \mathrm{~h}$ and the CAT activity was measured as previously described $(2,25)$. The average CAT activity for the triplicates was calculated for those cells transfected with plasmid without treatment as the baseline and for those cells transfected with plasmid treated with $800 \mathrm{~J} / \mathrm{m}^{2} \mathrm{UV}$ light as the percentage of residual repair activity (percent CAT activity) to estimate the DNA repair capacity (2).

\section{The FISH Procedure}

pCMVcat was also used as the probe in the FISH procedure. The probe DNA was labeled with digoxigenin-11-dUTP (Boehringer Mannheim, Indianapolis, IN, USA) using a nick-translation kit (Life Technologies). The hybridization protocol of 


\section{Research Reports}

Table 1. Differential Transfection Efficiency, Reporter Gene Expression and DNA Repair Capacity of Fibroblasts and Lymphoblastsa

\begin{tabular}{|c|c|c|c|c|c|}
\hline \multirow[b]{3}{*}{ Cell Lines } & \multicolumn{3}{|c|}{ Transfection Efficiency } & \multirow{3}{*}{$\begin{array}{l}\text { CAT Activity } \\
(\text { (cpm) }\end{array}$} & \multirow{3}{*}{$\begin{array}{c}\text { DNA } \\
\text { Repair } \\
\text { Capacity (\%)C }\end{array}$} \\
\hline & \multirow{2}{*}{$\begin{array}{l}\beta-G a l(\%) \\
\text { at } 40 \mathrm{~h}\end{array}$} & \multicolumn{2}{|c|}{ FISH (\%) } & & \\
\hline & & at $1 \mathrm{~h}$ & at $40 \mathrm{~h}$ & & \\
\hline \multicolumn{6}{|c|}{ Lymphoblastoid Cells } \\
\hline \multicolumn{6}{|c|}{ Repair-proficient } \\
\hline GM00892B & $1.0 \pm 1.0$ & $72.1 \pm 6.9$ & $49.0 \pm 4.4$ & $19339 \pm 269$ & $34.7 \pm 1.9$ \\
\hline GM00131A & $1.3 \pm 0.6$ & $65.5 \pm 3.8$ & $37.0 \pm 3.6$ & $12508 \pm 1526$ & $16.7 \pm 1.0$ \\
\hline \multicolumn{6}{|l|}{ Repair-deficient } \\
\hline GM02246B & $0.67 \pm 0.6$ & $74.0 \pm 5.8$ & $52.3 \pm 4.5$ & $10921 \pm 1424$ & $0.1 \pm 0.1$ \\
\hline GM02345B & $0.67 \pm 0.6$ & $72.4 \pm 3.9$ & $48.4 \pm 2.6$ & $13249 \pm 1411$ & $0.5 \pm 0.3$ \\
\hline \multicolumn{6}{|l|}{ Fibroblasts } \\
\hline \multicolumn{6}{|l|}{ Repair-proficient } \\
\hline GM3377B & $6.3 \pm 1.5$ & $88.7 \pm 4.2$ & $75.0 \pm 6.3$ & $28616 \pm 967$ & $51.0 \pm 12$ \\
\hline \multicolumn{6}{|l|}{ Repair-deficient } \\
\hline GM5509B & $6.0 \pm 1.0$ & $84.2 \pm 3.7$ & $74.1 \pm 3.2$ & $25824 \pm 4444$ & $5.3 \pm 3.2$ \\
\hline \multicolumn{6}{|c|}{$\begin{array}{l}\text { aAll the data are presented as means } \pm \text { standard deviations from two independent experiments. } \\
\text { bBaseline expression of undamaged pCMVcat in the cells. }\end{array}$} \\
\hline
\end{tabular}

Pinkel et al. (19) was used with minor modifications. Briefly, the labeled probe $(1 \mu \mathrm{g})$ was concentrated with a SpeedVac ${ }^{\circledR}$ (Savant Instruments, Holbrook, NY, USA) for $1 \mathrm{~h}$, dissolved before being completely dried in $5 \mu \mathrm{L}$ of double-distilled water and stored at $-20^{\circ} \mathrm{C}$ for later use. Because in our initial experiments DNase treatment immediately after transfection had no effect on transfection efficiency, DNase treatment was omitted in later experiments. The transfected fibroblasts were grown on slides in $100-\mathrm{mm} \times 20-\mathrm{mm}$ culture dishes, and the lymphoblasts were attached to frosted slides by lowspeed centrifugation $(600 \mathrm{rpm})$ with a Cytospin 3 (Shandon, Pittsburgh, PA, USA). The cells were then dehydrated with a series of ethanol treatments (75\%, 80\%, 95\% and $100 \%$; each for 2 $\mathrm{min})$, denatured with $70 \%$ ( $\mathrm{vol} / \mathrm{vol})$ formamide $/ 2 \times$ standard saline citrate (SSC; $\mathrm{pH} \mathrm{7.0)} \mathrm{at} 75^{\circ} \mathrm{C}$ for $2 \mathrm{~min}$ and dehydrated again with a series of ethanol treatments $(75 \%, 80 \%, 95 \%$ and $100 \%$; each for $2 \mathrm{~min}$ ) at $-20^{\circ} \mathrm{C}$ instead of the usual $4^{\circ} \mathrm{C}$, which significantly increased hybridization efficiency. For hybridization, $10 \mu \mathrm{L}$ of cocktail containing $225 \mathrm{ng}$ of DNA probe were added to each slide on the area containing cells; and the cells were covered with a $25-\mathrm{mm} \times 25-\mathrm{mm}$ glass coverslip sealed with rubber cement and incubated in a prewarmed humidified chamber at $37^{\circ} \mathrm{C}$ for $20 \mathrm{~h}$. After hybridization, the slides were washed three times at $41^{\circ} \mathrm{C}$ for 5 min each time with $50 \%$ formamide $/ 2 \times \mathrm{SSC}$ and twice at $41^{\circ} \mathrm{C}$ for

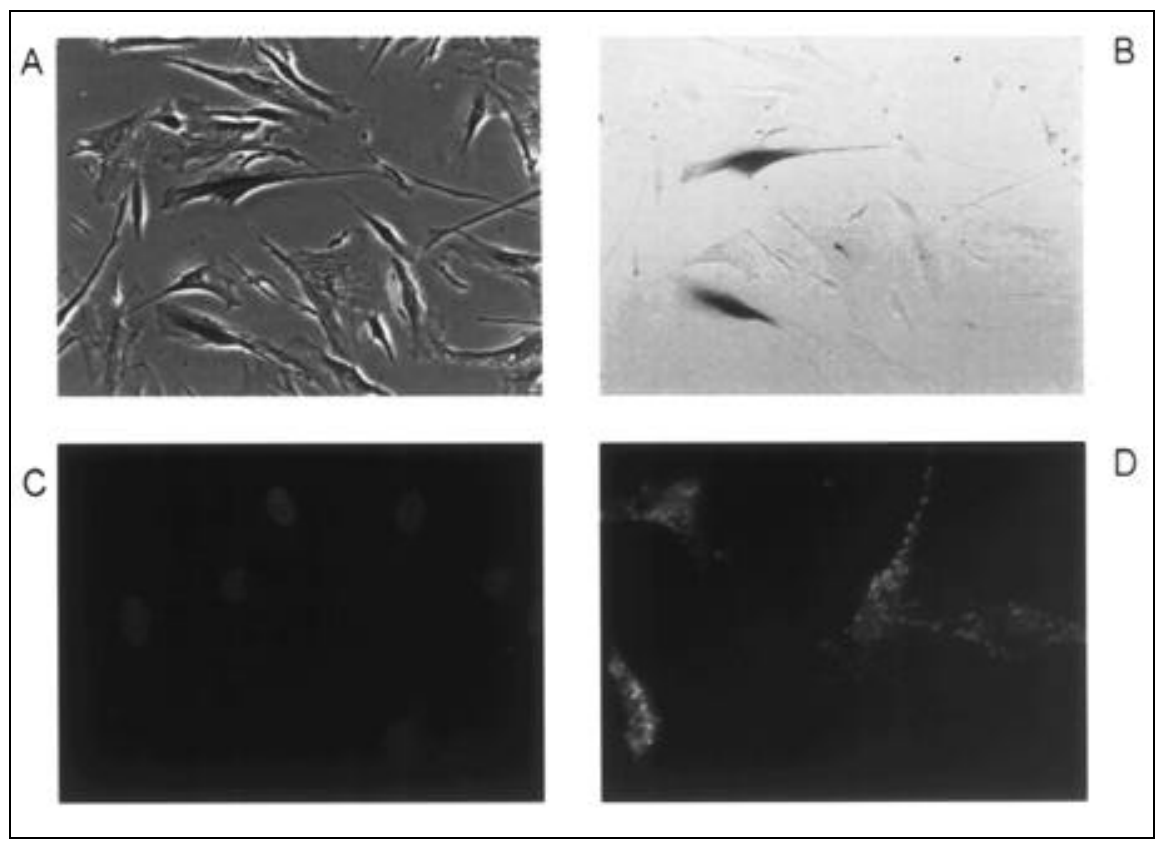

Figure 1. Comparison of cotransfection and FISH methods for measuring transfection efficiency of GM03377B fibroblasts. (A and B) Cotransfected cells stained for $\beta$-gal examined by light microscopy. Phase contrast (A) and bright-field (B) view of the same field. (C) FISH of untransfected cells, whose nuclei (blue) were counterstained by DAPI only. (D) FISH of cells transfected with the pCMVcat plasmids stained by digoxigenin-rhodamine $1 \mathrm{~h}$ after transfection. pCMV cat (red) was located in the cytoplasm. All photomicrographs were taken with a $40 \times$ objective. 
damine detection kit (Oncor, Gaithersburg, MD, USA) according to the manufacturer's instructions, and the slides were washed three times at room temperature for $2 \mathrm{~min}$ each time with the sodium bicarbonate/Tween ${ }^{\circledR}-20$ buffer ( $\mathrm{pH}$ 8.0). Counterstaining was then performed with 4',6-diamidino-2-phenylindole (DAPI) (Oncor).

\section{The $\beta$-Gal Assay}

For the $\beta$-gal assay, transfected fibroblasts were grown in six-well plates and transfected lymphoblasts in test tubes. The cells were assayed for $\beta$-gal expression at $40 \mathrm{~h}$ after transfection when the level of expression reached its maximum. The cells were stained in situ for $\beta$-gal by following a published procedure (20) with minor modifications. The staining was performed by adding 5-bromo-4-chloro-3-indolyl- $\beta$ D-galactopyranoside (X-gal) and the scoring was recorded $6 \mathrm{~h}$ later, because in the initial experiments, in which the scoring was evaluated at 1,6 and $12 \mathrm{~h}$, maximal staining was noted at $6 \mathrm{~h}$ after the addition of X-gal (data not shown).

\section{Computerized Photography}

All slides were examined using a Zeiss photomicroscope equipped with a mercury UV lamp (Carl Zeiss, Thornwood, NY, USA). The images were digitized with an Optimas Images Analysis System (Optimas Corporation, Bothell, WA, USA).

\section{Calculation of Transfection Efficiency}

The transfection efficiency was calculated as the percentage of cells stained by either the FISH method or the $\beta$-gal assay. For each efficiency calculated, 100 cells were randomly examined microscopically on each of three slides. Reconstruction assays were used to evaluate the accuracy of the FISH procedure in measuring the transfection efficiency. In these assays, various proportions of untransfected and transfected GM00892B cells were mixed and assayed by FISH. The observed transfection efficiencies of different mixtures were compared with the expected efficiencies, which were estimated by multiplying the transfection efficiency of a population of all transfected cells by the percentage of the transfected cells in the mixture.

\section{RESULTS}

Figures 1 and 2 show pCMVcattransfected cells detected by FISH (red) and $\beta$-gal staining (blue; Figure 1 ), respectively. Transfection efficiencies measured by either the FISH or pCMV$\beta$ gal method were higher in the fibroblasts than in the lymphoblasts (Table 1). It can be seen that transfected plasmid was located in the cytoplasm $1 \mathrm{~h}$ after transfection and no false-positive cells were observed among the untransfected cells (Figures 1C and 2B). However, these results do not rule out the possibility of false negatives (i.e., transfected cells not detected), because plasmid may be undetectable because the level of plasmid is too low or the fluorescence signal is too weak to be seen.

To verify the accuracy of the FISH procedure, we performed a reconstruction assay. The observed percentages of positive cells were very close to the expected percentages. For example, with the observed transfection efficiency of $69.2 \%$ (with a standard deviation $\pm 2.5 \%$ ) in a mixture of $60 \%$ transfected cells and $40 \%$ untransfected cells, one would expect $41.5 \%$ (i.e., $69.2 \times 0.6$ ) positive cells, which was close to the observed number $(41.9 \% \pm 2.0 \%)$. For the mixture of $40 \%$ transfected cells and $60 \%$ untransfected cells, the observed and expected frequencies were $25.1 \% \pm 3.9 \%$ and $27.7 \%$, respectively. These results indicated that the FISH procedure is highly consistent and accurate.

Because we were interested in the transfection efficiencies of cells used in the HCR assay, we further measured transfection efficiencies by the FISH method and reporter gene expression by the HCR assay in DNA repair-proficient (GM00892B, GM00131A and GM03377B) and DNA repair-deficient (GM02246B, GM02345B and GM05509B) cells $40 \mathrm{~h}$ after transfection (Table 1). Transfection efficiencies measured by the FISH method at $40 \mathrm{~h}$ were $30 \%$ to $45 \%$ lower in lymphoblast cells and $10 \%$ to $15 \%$ lower in fibro- 
blasts as compared to those measured by the FISH method $1 \mathrm{~h}$ after transfection. It appears that by some unknown mechanism, the transfected plasmids were lost from some of the cells $40 \mathrm{~h}$ after transfection. This might be explained by a combination of degradation and dilution of unreplicated pCMVcat (10) that does not integrate into the genome (2). Most of the remaining transfected pCMVcat was still in the cytoplasm (data not shown). Although the majority of transfected plasmids were seen in the cytoplasm, it was difficult to distinguish those plasmids in the cytoplasm overlaying the nucleus from those actually in the nucleus. In addition, a small proportion of the plasmids in the cytoplasm may have actually entered the nucleus and, therefore, were undetected by FISH.

Transfection efficiencies of lymphoblast cells as measured by the FISH method $1 \mathrm{~h}$ after transfection were significantly correlated with those $40 \mathrm{~h}$ after transfection $(P<0.01)$, but neither was correlated with baseline expression of the reporter gene or with the DNA repair capacity of the cells. Rather, the reporter gene expression level was a function of the number of cells used for

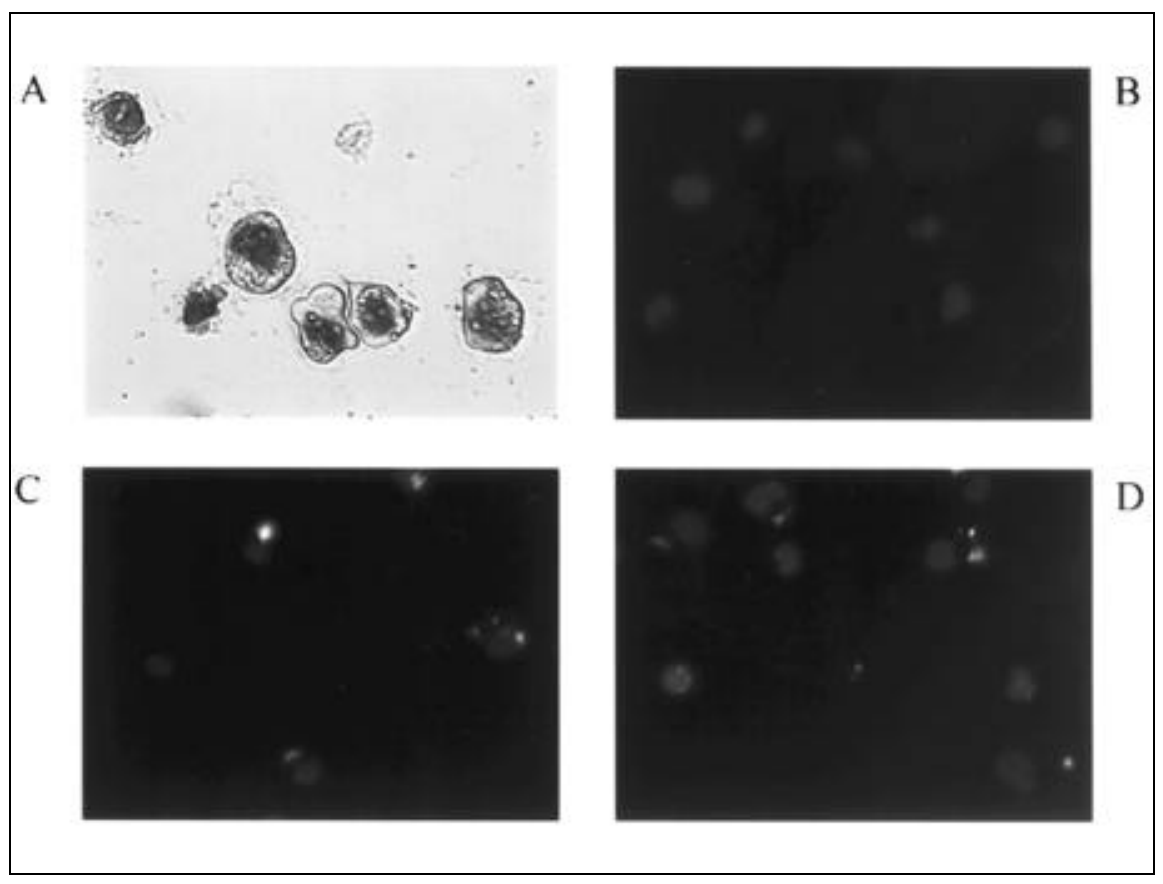

Figure 2. FISH measurement of transfection efficiency in GM00131A lymphoblasts. FISH was performed $1 \mathrm{~h}$ after transfection and revealed that pCMV cat (red) was located in the cytoplasm. (A) Giemsastained cells; (B) untransfected cells; (C) cells transfected with undamaged pCMVcat; (D) cells transfected with pCMV cat damaged by exposure to $800 \mathrm{~J} / \mathrm{m}^{2} \mathrm{UV}$ light before transfection. the transfection (data not shown). It was not surprising that transfection efficiencies measured by the FISH method did not predict the level of reporter gene expression, because each positive cell may contain different numbers of plasmids or, more relevantly, different numbers of plasmids that may have entered the nuclei and been expressed. However, these results were limited because of the small number of cell lines tested.

We also compared the transfection efficiencies of UV-damaged plasmid and undamaged plasmid in GM00131A cells. As shown in Figure 2, transfection efficiencies measured by the FISH method were similar for undamaged plasmid (Figure 2C; 71.7\% $\pm 3.5 \%$ ) and UV-damaged $\left(800 \mathrm{~J} / \mathrm{m}^{2}\right)$ plasmid (Figure 2D; $71.3 \% \pm 4.2 \%$ ), indicating the UV damage did not affect the transfection efficiency.

\section{DISCUSSION}

We have demonstrated that the FISH method for measuring transfection efficiency is sensitive, specific, accurate and feasible. Furthermore, the transfec- tion efficiency measured one hour after transfection is sufficient for the comparison of different cells of interest. This FISH method, which can be an alternative to the $\beta$-gal method, uses the physical presence of transfected plasmids as the endpoint; therefore, it can provide information about the percentage of cells that have taken up the plasmid, and thus provide the means of evaluating the effect of plasmid DNA damage on transfection efficiency.

We have previously demonstrated in a large population study that the expression of undamaged pCMVcat in primary lymphocytes from both normal subjects and cancer patients is similar (24). According to published data, the highest transfection efficiency $(100 \%)$ was observed in mouse L cells transfected with lipofectin (6), but the measurement was based on the fluorescence of labeled lipofectin, not on CAT gene hybridization. The lowest measurement of transfection efficiency (1\%) was observed in Drosophila Kc cells transfected by calcium phosphate precipitation, as measured by an immunofluorescence method with antiCAT monoclonal antibody (4). Our data show that the classical DEAE-dextran transfection method yielded an efficiency of transfection of more than $70 \%$ in lymphoblasts and more than $80 \%$ in fibroblasts as measured by the FISH method. No substantial differences in transfection efficiencies were observed between the repair-proficient and repair-deficient cells or between transfections with undamaged and UVdamaged plasmids.

Although the FISH method does not provide information about the rate of expression of the transfected plasmids, it has several advantages over cotransfection. First of all, it is very specific and results in no false positives. Second, it reveals the physical location of transfected plasmids within the cells and provides accurate information for evaluating the efficiency of a transfection method. Third, it allows assessment of the effect of plasmid DNA damage on transfection efficiency, which affects reporter gene expression and, therefore, cannot be assessed by the cotransfection method. Finally, the high sensitivity of the FISH method will help us evaluate other therapeutic 
methods such as antisense and gene therapies, in which transfection efficiency is a highly relevant concern.

\section{ACKNOWLEDGMENTS}

We thank Drs. Lawrence Grossman and Francis Ali-Osman for making available the plasmids pCMVcat and pCMVßgal; Dr. Michael Siciliano for providing his expertise and Dr. Ying Zhao her expert assistance with the FISH experiments; Drs. Reuben Lotan and Margaret Spitz for their comments and suggestions; Dr. Maureen Goode for her editorial help with the manuscript preparation; and Ms. Joanne Sider and Ms. Sherry Powell for their assistance in preparation of the manuscript.

\section{REFERENCES}

1.Abrahams, P.J. and J.A. Van der Eb. 1975. In vitro transformation of rat and mouse cells by DNA from simian virus 40 . J. Virol. 16:206-209.

2.Athas, A.F., M. Hedayati, M.G. Matanoski, E.R. Farmer and L. Grossman. 1991. Development and field-test validation of an assay for DNA repair in circulating human lymphocytes. Cancer Res. 51:5786-5793.

3.Collins, C., W.L. Kuo, R. Segraves, J. Fuscoe, D. Pinkel and J.W. Gray. 1991. Construction and characterization of plasmid libraries enriched in sequences from single human chromosomes. Genomics 11:9971006.

4.Davies, J.A., C.F. Addison, S.J. Delaney, C. Sunkel and D.M. Glover. 1986. Expression of the prokaryotic gene for chloramphenicol acetyltransferase in Drosophila under the control of larval serum protein 1 gene promoters. J. Mol. Biol. 189:13-24.

5.de Wet, J.R., K.V. Wood, M. DeLuca and D.R. Helinski. 1987. Firefly luciferase gene: structure and expression in mammalian cells. Mol. Cell. Biol. 7:725-737.

6.Felgner, P.L., T.R. Gadek, M. Holm, R. Roman, H.W. Chan, M. Wenz, J.P. Northrop, G.M. Ringold and M. Danielsen. 1987. Lipofection: a highly efficient, lipid-mediated DNA-transfection procedure. Proc. Natl. Acad. Sci. USA 84:7413-7417.

7.Foecking, M.K. and H. Hofstetter. 1986. Powerful and versatile enhancer-promoter unit for mammalian expression vectors. Gene 45:101-105.

8.Fregeau, C.J. and R.C. Bleackley. 1991. Factors influencing transient expression in cytotoxic $\mathrm{T}$ cell following DEAE dextran-mediated gene transfer. Somat. Cell Mol. Genet. 17:239-257.

9.Hall, C.V., P.E. Jacob, G.M. Ringold and F. Lee. 1983. Expression and regulation of Es- cherichia coli lac $\mathrm{Z}$ gene fusion in mammalian cells. J. Mol. Appl. Genet. 2:101-109.

10.Watson, J.D., M. Gilman, J. Witkowski and M. Zoller (Eds.). 1992. Transferring genes into mammalian cells, p. 213-234. Recombinant DNA. W.H. Freeman and Company, New York.

11.Legerski, R.J., P. Liu, L. Li, C.A. Peterson, Y. Zhao, R.J. Leach, S.L. Naylor and M.J. Siciliano. 1994. Assignment of xeroderma pigmentosum group C (XPC) gene to chromosome 3p25. Genomics 21:266-269.

12.Lehmann, A.R. and A. Omen. 1985. Effect of DNA damage on the expression of the chloramphenicol acetyltransferase gene after transfection into diploid human fibroblast cells. Nucleic Acids Res. 13:2087-2095.

13.Levis, R., H. Huang and S. Schlesinger. 1987. Engineered defective interfering RNAs of Sindbis virus express bacterial chloramphenicol acetyltransferase in avian cell. Proc. Natl. Acad. Sci. USA 84:4811-4815.

14.Lichter, P., C.C. Tang, K. Call, G. Hermanson, G.A. Evans, D. Housman and D.C. Ward. 1990. High-resolution mapping of human chromosome 11 by in situ hybridization with cosmid clones. Science 247:64-69.

15.Lim, K. and C.B. Chae. 1989. A simple assay for DNA transfection by incubation of the cells in culture dishes with substrate for $\beta$ galactosidase. BioTechniques 7:576-579.

16.Liu, P., S.A. Tarle, A. Hajra, D.F. Claxton, P. Marlton, M. Freedman, M.J. Siciliano and F.S. Collins. 1993. Fusion between transcription factor $\mathrm{CBF} \beta / \mathrm{PEBP} 2 \beta$ and a myosin heavy chain in acute myeloid leukemia. Science 261:1041-1044.

17.McCuchan, J.H. and J.S. Pagano. 1968. Enhancement of the infectivity of simian virus 40 deoxyribonucleic acid with diethyaminoethyl-dextran. J. Natl. Cancer Inst. 41:351356.

18.Neumann, E., M. Schaefer-Ridder, Y. Wang and P.H. Hofschneider. 1982. Gene transfer into mouse lymphoma cells by electroporation in high electric fields. EMBO J. 1:841-845.

19.Pinkel, D., T. Straume and J.W. Gray. 1986. Cytogenetic analysis using quantitative, highsensitivity, fluorescence hybridization. Proc. Natl. Acad. Sci. USA 83:2934-2938.

20.Ray, J. and F.H. Gage. 1992. Gene transfer into established and primary fibroblast cell lines: comparison of transfection methods and promoters. BioTechniques 13:598-603.

21.Reddy, S.V., S. Takahashi, C. Haipek, J.M. Chirgwin and G.D. Roodman. 1993. Tartrate-resistant acid phophatase gene expression as a facile reporter gene for screening transfection efficiency in mammalian cell culture. BioTechniques 15:444-446.

22.Ried, T., A. Baldini, T.C. Rand and D.C. Ward. 1992. Simultaneous visualization of seven different DNA probes by in situ hybridization using combinational fluorescence and digital imaging microscope. Proc. Natl. Acad. Sci. USA 89:1388-1392.

23.Sheibani, N., M.M. Jennerwein and A. Eastman. 1989. DNA repair in cell sensitive and resistant to cis-diamminedichloroplatinum (II): host cell reactivation of damaged plasmid. Biochemistry 28:3120-3124.

24.Viegas-Péqignot, E., B. Dutrillaux, H.
Magdelenat and M. Coppey-Moisan. 1989. Mapping of single-copy DNA sequences on human chromosomes by in situ hybridization with biotinylated probes: enhancement of detection sensitivity by intensified-fluorescence digital-imaging microscopy. Proc. Natl. Acad. Sci. USA 86:582-586.

25.Wei, Q., G.M. Matanoski, E.R. Farmer, M. Hedayati and L. Grossman. 1993. DNA repair and aging in basal cell carcinoma: a molecular epidemiologic study. Proc. Natl. Acad. Sci. USA 90:1614-1618.

26.Weintraub, H., P.F. Cheng and K. Conrad. 1986. Expression of transfected DNA depends on DNA topology. Cell 46:115-122.

Received 21 September 1995; accepted 28 February 1996.

Address correspondence to:

Qingyi Wei

Box 189, Department of Epidemiology

The University of Texas

M.D. Anderson Cancer Center

1515 Holcombe Blvd.

Houston, TX 77030, USA

Internet:qwei@request.mda.uth.tmc.edu 